\title{
Code-Switching: A Pedagogical Strategy in Bilingual Classrooms
}

\author{
Severinus Sakaria ${ }^{1, *}$, Joko Priyana ${ }^{2}$ \\ ${ }^{1}$ English Education Department, Graduate School, Yogyakarta State University, Yogyakarta, Indonesia \\ ${ }^{2}$ English Education Department, Yogyakarta State University, Yogyakarta, Indonesia \\ *Corresponding author: sevensakaria@gmail.com
}

\begin{abstract}
This paper presents a critical review of research on the use of code-switching as an instructional strategy in the teaching and learning of foreign or second language in bilingual contexts. Necessitated by the emerging and existing body of negative criticisms about its interference with the target language acquisition, this library-based paper sets out to critically review the use of code-switching to fathom its support as a crucial teaching and learning tool for language instruction, particularly in English language teaching and learning environments. This paper takes a qualitative inquiry that draws arguments primarily from library documentation. It particularly draws inferences from various theoretical orientations and empirical evidence within the confines of second or foreign language acquisition underpinning the fundamental use of code-switching in foreign or second language classrooms. Specifically, the paper attempts to theoretically justify the utilization of code-switching particularly in relation to its rationales and functions and, most significantly, its pedagogical implications to the process of second or foreign language teaching and learning. It ends with some suggestions on how teachers should take advantage of its availability and consistently maximize its use in bilingual classrooms.
\end{abstract}

Keywords: code-switching, bilingual, pedagogical, language acquisition

Cite This Article: Severinus Sakaria, and Joko Priyana, "Code-Switching: A Pedagogical Strategy in Bilingual Classrooms." American Journal of Educational Research, vol. 6, no. 3 (2018): 175-180. doi: 10.12691/education-6-3-3.

\section{Introduction}

Over the past years, there has been an increasingly significant interest in the use of code-switching in the process of teaching and learning second or foreign languages, particularly English language. This interest has created a web of controversies and opposing views on the use of code-switching in bilingual classrooms for scholars and researchers. These divergent views have considerably occupied serious discussions on whether to use only the target language exclusively or to use it alongside the first or the predominant local language in second or foreign language classrooms.

Proponents of exclusive use of the target language in second or foreign language classrooms believe that by employing the target language exclusively as a learning model habituates students to building their own language system through communication practices while code-switching disinterests students in listening to the target language $[1,2,3,4,5]$ For these studies, it is clearly expected that the target language should be the main language to be used in foreign or second language classrooms, both as a language of instruction and communication. Amongst the reasons attached to this belief is that extensive language exposure to the target language will not only help students to achieve a native-like command of the language, but the exclusion of first language usage in second or foreign language classrooms will leave rooms for the target language to be the only students' primary source of their exposure [6,7]. Thus, in their views, the use of monolingual approach, for instance, teaching English through English, arguably introduces authenticity in the process of teaching and learning thereby substantially facilitating students' familiarity to the target language.

On the contrary, advocates of cross-lingual pedagogical strategy argue that the use of students' first language significantly enhances target language development and it should, therefore, be incorporated in the second or foreign language teaching and learning encounters [8-15]. To them, the integration of first language in the process of teaching and learning second or foreign languages essentially makes it easier not only for teachers in relation to grammar explanation and discipline but it also helps students to understand difficult concepts thereby subsequently consolidating their target language competencies.

Confronted by these conflicting views, the present paper seeks to theoretically analyze research that underscores the use of code-switching to ascertain its support as an instructional strategy and how its significant role enhances the development of students' second or foreign language competencies in bilingual classrooms. In reference to this, the paper draws inferences from various theoretical orientations and empirical evidence within the confines of second or foreign language acquisition underpinning its fundamental contribution to the teaching and learning of 
second or foreign languages in bilingual environments. It is therefore with this given background that this paper seeks to theoretically justify the utilization of codeswitching with particular focus on its functions and, most significantly, its pedagogical implications in the process of second or foreign language teaching and learning.

\subsection{The Concept of Code-Switching}

Before we wrestle around the concept of codeswitching, it is important to have a clear understanding of what the term "code" means. Due to its convoluted nature, the term code has been defined differently by various scholars. For example, in a very narrow sense, code encompasses a language or a dialect that forms as an integral part of a shared language diversity [16]. This notion corresponds well with that of Margana's [17] definition, who indicates that the term code refers not only to different languages, which include their dialects and styles but how these language varieties are dealt with within the same language. This implies that the term code embraces how people use the language within their communication. Besides that, a rather more complex definition is put forward by Gardner-Chloros [18], who contends that nowadays code is mostly referred to as a neutral rain shade term for languages, dialects, styles, registers and other language subsets that are primarily used to cover up different sub-divisions of a particular language. It is therefore not strange to find out that in bilingual or multilingual contexts, and in particular, bilingual classrooms, the application of two or more codes are often used in the communication practices, [19].

Code-switching, on the other hand, refers roughly to the use of at least two languages within a communication exchange. Code-switching is defined by [15] as a way of communication which entangles a speaker alternating between one language and another in communicative situation. Expressing a similar view, 29 relates the concept of code-switching to the way an individual who is bilingual alternates between two languages during his or her speaking engagement with another bilingual. In the same vein, code-switching is seen as a phenomenal switch of languages from one language to another language in a communicative phenomenon [20]. So, by virtue of these given definitions, it is highly expected that the speaker involved in such switching language circumstances should have a high level of at least basic communicative competency in both languages being alternated. Given these definitions, it clearly shows that code-switching is practiced for various reasons and functions. From the societal perspective, for example, [21] highlights that code-switching oftentimes occurs not only because of people's deficiency in the target language but because people want to get involved in conversation and make their opinions known to others. Hence, this clearly indicates that code-switching is performing a sociolinguistic function in this particular instance. From a classroom perspective, code-switching in the classrooms is mainly practiced as a tool for communication, both offering opportunities for students to understand the taught concepts well, and enhancing a smooth continuity of the classroom instruction [22]. This implies that the practice of code-switching in the classroom helps to fill the bridge of miscommunication between the teacher and the students particularly as regards to giving instruction, discipline and expressing key issues in an effort to facilitate equitable and enhanced teaching and learning.

Meanwhile, there are a handful of scholars with the notion that the use of code-switching should not be employed in second or foreign language classrooms. For example, a great number of scholars believe that exclusive use of English language by teachers in language classrooms should be strengthened as a learning model of English which leads to students habituated to using English in their communication practices $[1,4,5]$. For these scholars, the use of mother tongue or first language in second or foreign language classrooms hinders the acquisition of the target language. This implies that regular code-switching by language teachers demotivates students' interests in listening to the target language and eventually gains low proficiency in the target language [1] Reference [9] cautions that there is a chance that codeswitching might not be necessarily effective especially in linguistic classrooms which are diverse in nature, as the use of code-switching might disadvantage students with no shared mother tongue while those with a shared mother tongue are effectively being advantaged. In his research article, [15] finds out that some researchers are in favour of using first language while teaching the second language while some are against it. Those against the use of first language believe that learners do not have to understand everything said by the teacher and thus there is no real need for code-switching. He also believes that one is able to avoid the use of mother tongue by following certain techniques within the second or foreign language classroom. Thus, by applying those techniques, the language will become real and learners will build their own language system only when the target language is being used within the classroom.

Reference [7] forms part of various scholars who criticize the use of mother tongue in the process of teaching and learning English language. Not only, they urge classroom practitioners to create language-rich classrooms that promote the use of English in all English conducts and beyond, but also to teach English through English and encourage learners to interact with each other in English. Reference [7]'s views were supported by [4], who warn that although offering a first language equivalent may be viewed as a shortcut to building comprehension of what is being learned, it could nonetheless impoverish students' opportunity to attempt comprehension by inference. This notion is complemented by other studies which indicate that teachers do not often allow the use of first language on the ground of relevant language policies that prohibit its use in language classrooms, [2,3].

Nonetheless, the above views do not go well with a large segment of scholars in the sense that the exclusiveness of English use in language classrooms does not warrant achievement in the acquisition of foreign language and in English language in particular. This paper supports the use of code-switching in the process of teaching and learning as this phenomenon significantly contributes to the development of students' competence in the target language. Reference [8], for example, believes that while it is very easy to prevent using a foreign 
language, it is, however, very difficult to prevent using mother tongue because it is always available, and this is always a phenomenal temptation for both teachers and students. To clarify further, he theorizes the following:

Generally, L2 learning issues were using the native language, we have (1) learnt to think, (2) learnt to convey and (3) obtained an instinctive comprehension of structure. The mother tongue opens the door, not only to its own grammar, but to all grammars, inasmuch as it awakens the potential for universal grammar that lies within all of us. This foreknowledge is the result of interactions between a first language and our fundamental linguistic endowment, and is the foundation on which we build our Selves. It is the best resource individuals conveys to the assignment of remote dialect learning. Therefore, the first language is the ace key to remote dialects, the apparatus which gives us the speediest, surest, most exact, and most total methods for getting to an outside dialect. (p. 31).

This theory clearly spells out the significance of mother tongue not only as a cognitive and pedagogical tool but also as a crucial resource from which the teaching and learning of foreign language must be built on, particularly in bilingual classrooms. This resonates well with the assertion made by [7] who state that code-switching is advantageous especially when a classroom is the main or only source of students' exposure to the target language and students aim to use the language mainly in monolingual target language situations. Besides that, [23] indicate that code-switching is an important tool teachers can use to prevent negative transfer by alternating languages within the same sentence. This strategic translation makes an important contribution that enhances detailed input and at the same time arouses attention of the students to specific features of the target language and in the end, boosts up their vocabulary. Overall, as [10] put it, the incorporation of code-switching in bilingual classrooms strategically leads to an increased students' participation, inclusion, comprehension, and most significantly, to building and strengthening student-teacher interpersonal relationship.

\section{Methods}

This paper uses a qualitative inquiry that is based on library documentation. Given the ground that code-switching has considerably received a hefty of contending views, this paper finds it exceedingly important to review previous research underlying the significant contribution of code-switching to second or foreign language teaching. Therefore, this library-based paper theoretically analyzes research that support code-switching as a pedagogical strategy in bilingual classrooms. Firstly, the paper reviews previous studies that both corroborate and oppose the use of first language in second or foreign language classrooms. Secondly, it analyzes studies that underpin the incorporation of code-switching as regards to its functions in bilingual classrooms and particularly in order to ascertain its significant contribution to the development of students' target language. In the final analysis, the paper ends with the pedagogical implications with a particular focus on how teachers and students should maximize code-switching in their teaching and learning practices, much to the subsequent of acquiring the target language efficiently and effectively.

\section{Functions of Code-Switching in Bilingual Classrooms}

First language, or the predominant local language, serves various functions in the process of teaching and learning second or foreign languages. Hence, it is very important to acknowledge that many a time codeswitching is likely to occur in bilingual classrooms more especially in language classrooms where the teacher's first language is the same as that of the students [24,25,26]. This phenomenon is observed almost in all bilingual classrooms the entire globe over, and Indonesia is no exception. Ideally, teachers do employ code-switching as a correspondence between first language and second language in order to prevent breakdowns in students' comprehension of the language lesson. This employment of teaching strategy strategically maximizes students' use of second language by efficiently and effectively directing activities while using the first language. While a considerable amount of time may be needed to learn the target language, the switching practices in the process of teaching and learning may significantly increase students' exposure in the target language. Thus, code-switching is practiced not only to establish constructive social relationships and maintaining control over the classroom environment, but it is also used as a tool to communicate complex meanings to ensure that understanding is highly achieved [7]. In a bigger sense, while teachers can use code-switching as a tool to scaffold when communicating in the target language, code-switching can equally be used to maximize students' understanding as well as to support the comprehension of the language to keep the conversation ongoing. In addition, teachers normally employ students' native language as a teaching strategy mainly for instructions to help students' comprehension of material that would have been too cognitively difficult to understand without instruction in another language.

In English language classrooms, for example, codeswitching can be used as a tool to maintain classroom management in the sense that it serves as a powerful approach to execute orders as well as a means to emphasize important key terms [23]. It is also used to signal the preferred language choice in the classroom, and to mitigate the language preference to the target language. In addition, teachers often employ code-switching as a scaffold for learning, where the first language or mother tongue is used to explain cognitively difficult or new concepts. This means that code-switching, as a pedagogical strategy in second or foreign language classrooms, keeps the conversation ongoing by translating new vocabulary or by repeating a whole sentence from target language to first language and vice versa [27]. Moreover, teachers use code-switching to enhance the expression of affection, which motivates students to keep talking.

In addition to that, teachers code switch not only because of lack of language proficiency and difficulty in finding appropriate words in the target language, but they also code-switch purposively for cultural reasons, 
politeness, and most significantly, for explaining difficult concepts in order increase their students' understanding on what is being learnt [20]. Translated understandably, teachers may bring in first language to comprehensively explain important aspects as some students might not be able to understand key issues being raised through the target language. Apart from these functions, it is indicated that message reiteration, message qualification, and interjection or sentence filler are also found to serve as functions of code-switching in the process of English teaching and learning [28]. For example, the insertion of first language interjections or subconscious markers is used by teachers as communication strategies. Relatively, teachers can also employ code-switching for knowledge construction, classroom management, interpersonal relations, and for expressing personal affective meanings.

Besides that, there are also other functions of students' code-switching in bilingual classrooms. These are equivalence, floor-holding, reiteration, and conflict control [27]. Firstly, it is indicated that students use lexical aspects of the target language and progressively use such equivalent items to switch to their mother tongue. This means that students normally use equivalence as defensive technique primarily due to the insufficiency of their linguistic competence of the language that is being learnt. This defensive strategy helps them to build their confidence to engage in continued communication thereby subsequently increasing their target language development. Secondly, students code switch for floor-holding purposes. This means that during interlocution in the target language, students oftentimes use gap fillers with their own first language as a result of insufficient command in the target language. While some scholars indicate that floor-holding is disadvantageous to students in the long run, [27] believes that it helps students to learn the target language by building on their own native language. The third function raised by [27] is reiteration. This function serves as a tool that reinforces students' understanding through repetition technique essentially by reemphasizing and clarifying what is being learned in their mother tongue. While alteration may be of particular benefit to students whose target language is significantly low, it may likewise negatively impact the acquisition of the target language of those whose target language proficiency is reasonably above basic threshold as a result of the first language transfer phenomena. Last but definitely not the least, students may also use code-switching as a conflict control mechanism. Eldridge emphasizes that conflict control is used by students in their pursuit to eschew erroneous interpretation of the intended meaning. Conflict control is usually employed to shun away possible misunderstanding of intended meaning particularly in cases where the target culture and local culture differ extensively.

\section{Pedagogical Implications}

Given the analysis of previous research, it is evidently clear that there is enormous consensus among researchers and scholars that view code-switching as a useful instructional technique for second or foreign language teaching and learning. It is therefore significantly important that teachers and students alike should maximize its use in the process of second or foreign language teaching and learning. This is crucial because the use of mother tongue, or if you like, first language or the predominant local language within the close proximity of the environment, is widely practiced in foreign or second language classrooms. In Indonesia, for instance, Bahasa Indonesia is the official language and dominant language spoken in Indonesia. One would then assume Bahasa Indonesia to be the first language of the majority of Indonesians, although Indonesian curriculum sets English to be taught optionally as a local content in elementary school level, and progressively continues to be a compulsory subject from junior high school up until the university level and beyond [19]. This implies that the use of first language, which in most cases is the dominant language used outside the classroom, is likely to be integrated in the process of teaching and learning in English language classrooms. Reference [7] share the same sentiments and propose some ways on how to use first language and the target language in the classroom, especially when a teacher has the same mother tongue with the students, particularly in second or foreign language classroom circumstances. Given that there is a great number of research that support the use of code-switching, it is significantly important that teachers should take advantage of this noble proposition as it considerably contributes to students' target language acquisition. As [3] already puts it, teachers should employ code-switching in their teaching practices, particularly for grammar explanation and discipline. Given the low level of target language concentration outside the classrooms, the employment of their native language is of great importance to building their understanding because, understandably, their linguistic background in the target language will disinterestedly lower their motivation to learn the language.

Furthermore, as [21] rightfully puts it, code-switching is crucial for language development as it allows effective transfer of ideas from the teacher to the students and vice versa. It is with this notion that code-switching should be exposed to students at the early stages of learning as this exposure endows students to have motivation towards effective and successful learning and progressively become proficient speakers of a target language. In addition, teachers should make use of inter-sentential code switching particularly when giving detailed explanation and giving instruction. This creates a conducive environment and arouses students' interest to engage in classroom discussions and in the process, more responses will be drawn out as the driving force for such high-frequent occurrence of intersentential code-switching. For effective and efficient English language teaching and learning, for instance, [29] advises teachers to use code-switching not only as a means to point out main learning themes and other key tasks but also to point out students' errors and to give immediate correction. This practice does not only enhance students' learning of the English language, as [30] discover, but it also does improve students' engagement in answering questions which subsequently leads to an enhanced teaching and learning of the English language. Equally important, teachers' use of code-switching in the target language instruction can assist the students in understanding the materials due to their lack of target 
language proficiency. Switching from English to Indonesian, for instance, or any other language can also be employed as communication strategy in English classroom instruction. Given the low level of students' linguistic competence in English language, teachers should, therefore, use codeswitching as a resource of strengthening their students' comprehension thereby strengthening their linguistic competence in English language in the process.

\section{Conclusion}

The principal argument of this paper stresses that codeswitching is one of the potential strategies of second or foreign language, specifically English language, teaching and learning process in bilingual environments. To illustrate its potentiality, the paper critically reviews relevant literature regarding the practicality of pedagogical functions code-switching plays in bilingual foreign language settings. In reference to the above examination, it clearly indicates that alternating languages during the process of teaching and learning second or foreign languages, specifically English language, becomes a common practice in bilingual contexts. This observation puts aside the notion that code-switching is practiced subconsciously by English teachers during their classroom teaching practices. While this paper acknowledges the notion that excessive use of first language in second or foreign language classrooms may lead to students being overly dependent, it nonetheless encourages teachers to use it in a complete view of it as a teaching and learning tool that facilitates students' knowledge construction in the target language, and most significantly, that it enhances interpersonal interaction between themselves and the students, much to the ultimate increase of teaching and learning efficiency. Thus, it is on this ground that this paper suggests that the use of first language may not be equivalent to that of a target language, but it should only be used as a facilitating tool that teachers may use to assist their students' learning of a target language. In fact, the use of first language should be seen more in light of mitigating students' unnecessary insecurities that arise as a result of their limited language proficiencies in their diverse nature. Although code-switching on its own is a pedagogical strategy, its usage may only be maximized in the event that it produces outstanding outcomes rather than used as a mere teaching and learning technique. It must also be strictly reemphasized that students' first language is an extraordinarily powerful realm that should not be ignored in second or foreign language classrooms. It is, therefore, teachers' onus to conceptualize the effectiveness of students' first language and to aggressively use it to positively maximize the development of students' target language proficiencies. Last but definitely not the least, it is important to emphasize that the nature of this study is based on literature review which predominantly draws from theoretical orientations and practices. This naturally follows that the results presented herewith may have not been extensively and comprehensively proven empirically. Thus, this paper is strongly of the view that further research may be needed to explore more on how code-switching facilitates the development of students' target language.

\section{References}

[1] Adebola, O. A. "Code-switching and its Literacy Effects on the Acquisition of English Language by Yoruba / English Language Bilinguals". Journal of Education and Practice, 2(5), 2011.

[2] Auerbach, R. E. "Reexamining English Only in the ESL Classroom", TESOL Quarterly, 27(1), 9-32, 1993.

[3] Macaro, E. "Analysing student teachers' code-switching in foreign language classrooms: Theories and decision making", Modern Language Journal, 85 (4), 531-548, 2001.

[4] Macaro, E., and Lee, H. J. "Teacher Language Background, Codeswitching, and English-Only Instruction: Does Age Make a Difference to Learners' Attitudes", TESOL QUARTERLY, 47(4), 717-742, 2013.

[5] Mokibelo, E. "Code-Switching: a Strategy for Teaching and Learning or a Problem in Botswana", Research \& Reviews: Journal of Educational Studies, 2(4), 2016.

[6] Cummins, J. "Rethinking monolingual instructional strategies in multilingual classrooms", Canadian Journal of Applied Linguistics, 10(2), 221-240, 2007.

[7] Littlewood, W., \& Yu, B. "First language and target language in the foreign language classroom", Language Teaching, 44(1), 6477, 2011.

[8] Butzkamm, W. "We only learn language once. The role of the mother tongue in FL classrooms: death of a dogma", The Language Learning Journal, 28(1), 29-39, 2003.

[9] Cook, V. "Using the first language in the classroom", The Canadian Modern Language Review, 57, 402-423, 2001

[10] Creese, A., and Blackledge, A. "Translanguaging in the Bilingual Classroom: A Pedagogy for Learning and Teaching", The Modern Language Journal, 94(1), 103-115, 2010.

[11] Jamshidi, A., and Navehebrahim, M. "Learners Use of CodeSwitching in the English as a Foreign Language Classroom", Australian Journal of Basic and Applied Sciences, 7(1), 186-190, 2013.

[12] Jegede, O. "Code Switching and its Implications for Teaching Mathematics in Primary Schools in Ile-Ife, Nigeria", Journal of Education and Practice, 2(10), 2011.

[13] Jingxia, L. "Teachers' Code-Switching to the L1 in EFL Classroom", The Open Applied Linguistics Journal, 2010, 3, 1023, 2010.

[14] King, R. J., and Chetty, R. "Codeswitching: Linguistic and literacy understanding of teaching dilemmas in multilingual classrooms", Linguistics and Education, 25, 40-50, 2014.

[15] Stylianou-Panayi, N. "Code Switching in an EFL Environment", Linguistics and Literature Studies, 3(6), 259-263, 2015.

[16] Boztepe, E. Issues in Code-Switching: Competing Theories and Models. Issues in CS: Competing Theories and Models, 3(2), 2003

[17] Margana. "Promoting Code-switching practice to teach other subjects through English". Proceedings on International Conference at Muhamadiayah University of Purwokerto, 2010.

[18] Gardner-Chloros, P. Code-switching. Cambridge, Cambridge University Press, 2009.

[19] Margana. "Code-Switching In English Language Teaching: from Theory to Practice", Proceeding on International Conference at Sebelas Maret University, 2014.

[20] Ibrahim, E. H. E., Shah, M. I. A., and Armia, N. T. "CodeSwitching in English as a Foreign Language Classroom: Teachers' Attitude", English Language Teaching, 6(7) 139-150, 2013.

[21] Modupeola, R. O. "Code- Switching as a teaching strategy: Implication for English Language teaching and learning in a multilingual society", IOSR Journal Of Humanities And Social Science (IOSR-JHSS), 14(3), 92-94, 2013.

[22] Isaac, A. "An investigation into teacher's perception of the use of code-switching to facilitate comprehension in the area of language arts instruction in a primary school in the North Eastern Educational District", EDRS6900: Project Report. Unpublished thesis. University of West Indies, 2011.

[23] Turnbull, M., and Arnett, K. "Teachers' uses of the target and first languages in second and foreign language classrooms", Annual Review of Applied Linguistics, 22, 204-218, 2002.

[24] Cantone, F. K. Code-Switching in Bilingual Children. Dordrecht, Springer, 2007.

[25] Mouton, G. D. Code-Switching in Early English. Berlin: Hubert \& Co. $\mathrm{GmbH} \& \mathrm{Co}$. KG, Gottingen, 2011. 
[26] Mark, S., Mahootian, S., and Jonsson, S. Language Mixing and Code-Switching in Writing: Approaches to mixed-language written discourse, New York, Routledge, 2012.

[27] Eldridge, J. "Code-switching in a Turkish secondary school", ELT Journal, 50(4), 303-311, 1996.

[28] Cahyani, H., de Courcy, M., and Barnett, J. "Teachers' codeswitching in bilingual classrooms: exploring pedagogical and sociocultural functions", International Journal of Bilingual Education and Bilingualism, 2016.

[29] Street, J. H. "Code-switching in Iranian Elementary EFL Classrooms: An Exploratory Investigation", English Language Teaching, 4(1), 18-25, 2011.

[30] Simasiku, L., Kasanda, C., and Smit, T. "Can Code Switching Enhance Learners'Academic Achievement", Canadian Center of Science and Education, 8(2), 70-77, 2015. 